\title{
Avaliação zootécnica e qualidade da carcaça de frangos de corte alimentados com rações contendo farinha de peixe ou aveia branca
}

\author{
Performance and carcass quality of broilers fed with diets containing fish meal or white oat
}

\author{
Daiana Novello ${ }^{\mathrm{I}}$ Paulo Roberto Ost ${ }^{\mathrm{II}}$ Mikael Neumann ${ }^{\mathrm{II}}$ Ricardo Alves da Fonseca ${ }^{\mathrm{III}}$ \\ Sebastião Gonçalves Franco ${ }^{\mathrm{IV}}$ Daiana Aparecida Quintilianov
}

\section{RESUMO}

O presente trabalho objetivou analisar o desempenho zootécnico e a composição química da carne dos frangos (peito e coxa/sobrecoxa) alimentados com diferentes rações, contendo farinha de peixe ou aveia branca. Foram testados 5 tratamentos, com 5 repetições, com 10 aves por unidade experimental, totalizando 250 animais criados, de 1 a 40 dias de idade. Os frangos foram alojados em gaiolas, recebendo rações contendo 4,5 e 9\% de farinha de peixe, ou 10 e $20 \%$ de aveia branca, e ração controle. As análises químicas de umidade, cinzas, proteína bruta e extrato etéreo foram feitas em um animal de cada repetição. Não foram observadas diferenças $(P>0,05)$ para o consumo de ração, $o$ ganho de peso diário e a conversão alimentar. Não houve diferença $(P>0,05)$ na composição química da carne do peito de frango. No corte coxa/sobrecoxa analisado, o tratamento com inclusão de $9 \%$ de farinha de peixe proporcionou aumento significativo de lipídios em relação à ração controle e àquela com inclusão de $20 \%$ de aveia branca. Conclui-se, portanto, que é possivel utilizar os 4 tipos de rações teste sem interferir no desempenho das aves, sendo que a inclusão de $9 \%$ de farinha de peixe e de 10\% de aveia aumentaram os lipídios na carne da coxa/sobrecoxa dos frangos.

Palavras-chave: aves, alimentação animal, qualidade da carne.

\section{ABSTRACT}

The present research was aimed at analyzing the performance and the chemical composition of the chicken meat (chest and thigh/on-thigh) fed with different rations containing fish meal or white oat. Five treatments with 5 repetitions with 10 birds for each experimental unit had been tested, totalizing 250 animals created, from 1 to 40 days old. The chickens had been lodged in cages receiving rations contend $4.5 \%$ and $9 \%$ of fish meal, or, $10 \%$ and $20 \%$ of white oat, and the control diet. The chemical analyses of humidity, ashes, rude protein and ether extract were done in an animal for each repetition. It was not observed difference $(P>0.05)$ for the ration consumption, gain of daily weight and alimentary conversion. There was no difference $(P>0.05)$ in the chemical composition of the chest broiler meat. In the thigh/on-thigh analyzed, the treatment including 9\% of fish meal provided significant increase of lipids in relation to the control diet and to that including $20 \%$ of white oat ration. It is conclude, that it is possible to use the 4 types of rations tested without intervening in the birds performance, being that, the $9 \%$ of fish flour inclusion and $10 \%$ of oat had increased the lipids in the chickens thigh/on-thigh meat.

Key words: birds, animal feeding, quality of meat.

\section{INTRODUÇÃO}

A necessidade de existir informações atualizadas, adequadas e confiáveis sobre a composição de alimentos está cada dia mais relevante. A globalização da economia, bem como os avanços da nutrição, a presença de novos alimentos, as novas

\footnotetext{
'Departamento de Nutrição, Universidade Estadual do Centro-Oeste-PR (UNICENTRO), Rua Camargo Varela de Sá, 03, Bairro Vila Carli, 85040-080, Guarapuava, PR, Brasil, E-mail: nutridai@pop.com.br.

"Departamento de Medicina Veterinária, UNICENTRO, Guarapuava, PR, Brasil.

"'Curso de Ciências Biológicas, Universidade Estadual do Paraná, Faculdade Estadual de Filosofia, Ciências e Letras de Paranaguá, Paranaguá, PR, Brasil.

Iv Curso de Pós-graduação em Ciências Veterinárias, Universidade Estadual do Paraná (UFPR), Curitiba, PR, Brasil.

v'Departamento de Nutrição, UNICENTRO, Guarapuava, PR, Brasil.
} 
substâncias de importância para a saúde humana, o controle da segurança alimentar e a situação de saúde das populações são fatores que apontam para a necessidade do conhecimento da composição dos alimentos, o que é de muita importância para os países, principalmente no que diz respeito à disseminação da informação para os diferentes tipos de consumidores (FAO, 2002).

No ano de 2005, foram produzidas no Brasil cerca de oito milhões de toneladas de carne de frango, 16,4\% da produção mundial (SILVA, 2005). O consumo de $35,1 \mathrm{~kg}$ de carne de frango por habitante por ano coloca o país entre aqueles de maior utilização do produto. Os modernos processos de criação e industrialização, associados à melhoria genética das aves, têm levado a excelentes índices de conversão alimentar, precocidade, produtividade e sobrevivência (RICHETTI \& SANTOS, 2000).

Com os freqüentes aumentos nos preços de grãos de cereais e suplementos protéicos vegetais usados na alimentação dos animais, tem-se iniciado o interesse pelo aproveitamento de alimentos conhecidos como "não-convencionais". Uma maior lucratividade poderá surgir do uso racional de resíduos ou subprodutos agro-industriais (NASCIMENTO et al., 2005).

Do total da captura mundial de peixes, cerca de $72 \%$ são utilizados nos mercados de pescados frescos, congelados, enlatados e salgados; os $28 \%$ restantes seguem para a produção de ração animal. Assim, as partes não-comestíveis somam 20 milhões de toneladas, o que deve ser aproveitado pela indústria de nutrição animal (MORALLES-ULLOA \& OETTERER, 1995). A farinha de peixe é elaborada a partir de uma grande variedade de espécies de peixe. Tem excelente balanço de aminoácidos, sendo rica em metionina, lisina, cálcio e fósforo (BUTOLO, 2002; FIALHO, 2004; RIBEIRO et al., 2005).

A aveia branca é um cereal de excelente valor nutricional. Este cereal é cultivado principalmente nos Estados do Sul do país (ALMEIDA, 1998). Destaca-se por seu teor e qualidade protéica e por sua maior porcentagem de lipídios, que varia de 3,10 a 10,90\%, distribuídos por todo o grão e com predominância de ácidos graxos (AG) insaturados (LÀSZTITY, 1998).

O presente trabalho teve como objetivo analisar o desempenho zootécnico dos frangos de corte, bem como avaliar a composição química da carne destes animais (peito e coxa/sobrecoxa) alimentados com rações contendo farinha de peixe ou aveia branca e ainda comparar os resultados encontrados com as tabelas de composição química de alimentos para humanos mais utilizadas.

\section{MATERIAL E MÉTODOS}

O experimento foi conduzido no Laboratório Animal do Departamento de Nutrição do Centro de Ciências da Saúde da UNICENTRO, no período de 05 de janeiro a 13 de fevereiro de 2004, em Guarapuava, no Paraná, e teve duração de 40 dias. Foram avaliados cinco tratamentos, com cinco repetições, sendo dez frangos (machos) por unidade experimental (gaiola), perfazendo um total de 250 animais. Utilizou-se uma linhagem híbrida comercial com peso médio inicial de 38 gramas. Os tratamentos experimentais foram os seguintes: 1- ração-referência; 2 - 4,5\% de farinha de peixe; 3 - 9\% de farinha de peixe; $4-10 \%$ de aveia branca; 5 - 20\% de aveia branca. As rações foram isoprotéicas e isoenergéticas.

Todas as aves foram alojadas em gaiolas com comedouros individualizados. $\mathrm{O}$ ambiente foi climatizado com aquecedores a gás e exaustores de teto, durante todo o período experimental.

Os dois alimentos-teste foram incluídos em uma ração testemunha (grupo controle) (Tabela 1), calculada segundo ROSTAGNO et al. (2000). Ração e água foram fornecidas ad libitum. Durante o período experimental, foi utilizada apenas uma única ração, pois foi considerada uma só fase durante o experimento. Isso pode ser justificado na tentativa de manter os mesmos níveis dos alimentos-teste do início ao final do experimento, para evitar modificações que poderiam influenciar no valor nutricional da carne a ser avaliada. No final do período experimental, todas as aves foram pesadas individualmente, sendo separado um animal de cada repetição, de peso médio do box, para avaliação de carcaça, após jejum de seis horas. Os animais selecionados foram identificados, abatidos e congelados a $-18^{\circ} \mathrm{C}$, até sua análise química.

Para as análises bromatológicas, as carcaças foram descongeladas em refrigerador com temperatura aproximada de $10^{\circ} \mathrm{C}$ por 24 horas. Após descongeladas, foram eliminadas das amostras de peito e de coxa/ sobrecoxa toda a gordura visível e a pele. Após isso, foram realizadas as análises de umidade e cinzas no laboratório de Engenharia de Processos da UNICENTRO, em Guarapuava-PR. O restante das amostras foram colocadas em bandejas etiquetadas e secadas em estufa com ar circulante a $55^{\circ} \mathrm{C}$, por 24 horas, para retirada da umidade. As amostras secas foram enviadas para o Laboratório de Análises FísicoQuímicas da EMBRAPA Suínos e Aves, para serem efetuadas as análises de proteína bruta e extrato etéreo.

Foram utilizadas diferentes metodologias. Na determinação da umidade e cinzas, utilizou-se o procedimento segundo o Instituto Adolfo Lutz (1985). 
Tabela 1 - Composição centesimal das rações utilizadas no experimento.

\begin{tabular}{|c|c|c|c|c|c|}
\hline \multirow{2}{*}{ Ingredientes } & \multicolumn{5}{|c|}{ Quantidade (\%) } \\
\hline & Ração referência & Farinha de peixe $4,5 \%$ & Farinha de peixe $9 \%$ & Aveia branca $10 \%$ & Aveia branca $20 \%$ \\
\hline Milho grão & 59,30 & 62,68 & 63,45 & 49,31 & 38,05 \\
\hline Soja farelo $45 \%$ & 34,33 & 28,36 & 22,84 & 33,84 & 33,58 \\
\hline Peixe farinha 55\% & - & 4,50 & 9,00 & - & - \\
\hline Aveia branca & - & - & - & 10,00 & 20,00 \\
\hline Óleo de soja & 1,98 & 1,19 & 2,57 & 2,50 & 4,05 \\
\hline Fosfato bicálcico & 1,78 & 0,90 & 0,71 & 1,77 & 1,76 \\
\hline Calcário & 0,96 & 0,85 & 0,50 & 0,95 & 0,94 \\
\hline Arroz casca & 0,50 & 0,50 & 0,30 & 0,50 & 0,50 \\
\hline Sal comum & 0,44 & 0,37 & 0,20 & 0,43 & 0,43 \\
\hline Dl-metionina & 0,23 & 0,20 & 0,15 & 0,22 & 0,22 \\
\hline Px vitamínico-ave ${ }^{1}$ & 0,20 & 0,19 & 0,14 & 0,20 & 0,20 \\
\hline L-lisina $\mathrm{HCl}$ & 0,18 & 0,16 & 0,10 & 0,18 & 0,17 \\
\hline Px mineral-ave ${ }^{2}$ & 0,10 & 0,10 & 0,04 & 0,10 & 0,10 \\
\hline Total & 100,00 & 100,00 & 100,00 & 100,00 & 100,00 \\
\hline \multicolumn{6}{|c|}{ Composição calculada } \\
\hline Energia met. aves $\left(\mathrm{kcal} \mathrm{kg}^{-1}\right)$ & $2.950,00$ & $2.950,00$ & $2.950,00$ & $2.950,00$ & $2.950,00$ \\
\hline Proteína bruta & 21,04 & 21,04 & 21,04 & 21,04 & 21,04 \\
\hline Cálcio & 0,94 & 0,94 & 0,94 & 0,94 & 0,94 \\
\hline Fósforo disponível & 0,44 & 0,44 & 0,44 & 0,44 & 0,44 \\
\hline Lisina total & 1,24 & 1,24 & 1,24 & 1,24 & 1,24 \\
\hline Met + cistina total & 0,88 & 0,88 & 0,88 & 0,88 & 0,88 \\
\hline Metionina total & 0,55 & 0,56 & 0,55 & 0,54 & 0,54 \\
\hline Triptofano total & 0,26 & 0,24 & 0,23 & 0,26 & 0,27 \\
\hline Sódio & 0,22 & 0,22 & 0,22 & 0,22 & 0,22 \\
\hline Potássio & 0,81 & 0,74 & 0,66 & 0,81 & 0,81 \\
\hline Ácido linoléico & 2,44 & 1,68 & 1,65 & 2,53 & 3,16 \\
\hline Fibra bruta & 3,39 & 3,40 & 3,67 & 4,53 & 5,23 \\
\hline Cloro & 0,30 & 0,30 & 0,29 & 0,29 & 0,28 \\
\hline
\end{tabular}

1 - Mistura vitamínica: Vit. A, 10.000UI.; Vit. D 3 , 2000UI.; Vit. E, 30UI.; Vit. B 1 , 2,0mg; Vit. B 2 , 6,0mg; Vit. B 6 , 4,0mg; Vit. B Ác. pantotênico, 12,0mg; Biotina, 0,1mg; Vit. $\mathrm{K}_{3}$, 3,0mg; Ác. fólico, $1,0 \mathrm{mg}$; Ác. nicotínico, 50,0mg; Se, 0,25mg.

2 - Mistura mineral: Fe, 50mg; Co, 1,0mg; Cu, 10,0mg; Mg, 80,0mg; Zn, 50,0mg; I, 1,0mg.

A análise de lipídios totais foi realizada segundo metodologia AOAC (1995b). As proteínas totais foram quantificadas através do clássico método MicroKjedahl (AOAC, 1995a).

Os valores de composição química de carcaça foram comparados com as Tabelas de composição química de alimentos nacionais e internacionais para humanos, sendo elas a Tabela Brasileira de Composição de Alimentos - TACO (2004)e a do United States Department of Agriculture - USDA (1999).

A avaliação do consumo médio total de ração foi realizada no período de 1 a 40 dias, dividindose a quantidade de ração consumida pelo número de aves da parcela. Para o cálculo da conversão alimentar (CA) dos frangos do experimento, foi dividido o consumo médio total de ração pelo peso final dos frangos aos 40 dias.

Foi feita uma análise econômica simples em relação ao custo da ração para a produção de um quilo de frango vivo. Para computar o custo de cada quilo das diferentes rações, foram utilizados preços dos ingredientes comercializados na região de Guarapuava - PR. O custo do quilo de frango vivo por tratamento foi calculado multiplicando-se o custo do quilo de ração pela conversão alimentar obtida em cada tratamento.

Os dados estatísticos foram analisados utilizando-se o programa estatístico SISVAR (FERREIRA, 1999), através do delineamento inteiramente casualizado, sendo empregado, para comparação de médias, o teste de Tukey a um nível de significância de 5\%.

Ciência Rural, v.37, n.5, set-out, 2007. 


\section{RESULTADOS E DISCUSSÃO}

Os dados obtidos de consumo médio total de ração, peso médio das aves aos 40 dias e conversão alimentar das aves podem ser observados na tabela 2. Não foi encontrada diferença significativa entre os tratamentos $(\mathrm{P}>0,05)$ no desempenho das aves. Isso pode ser explicado, uma vez que em todos os tratamentos foram mantidos os mesmos valores nutricionais, principalmente de energia, que influencia diretamente o consumo de ração. Além disso os teores de fibra não atingiram níveis altos suficientes para influenciar negativamente no desempenho.

Pesquisas recentes avaliaram a substituição parcial da proteína do farelo de soja por farinha de peixe em rações de frangos em níveis de 0, 10, 20, 30, 40 e $50 \%$ da proteína do farelo de soja (PONCE \& GERNAT, 2002). Assim como no presente trabalho, esses autores não observaram diferenças significativas no desempenho dos frangos na fase de terminação.

Experimentos estudando a inclusão de farinha de peixe de 0, 25, 50, 75 e 100\% em substituição à proteína de farelo de soja em rações para frangos resultaram em diferenças $(\mathrm{P}<0,01)$ no peso da ave, no consumo e na conversão alimentar dos 7 até 42 dias de idade (MAIGUALEMA \& GERNAT, 2003), quando os animais receberem acima de $50 \%$ de farinha de peixe. Ainda, um trabalho comparando dietas para frangos com e sem farinha de peixe, em níveis de 4 a $8 \%$ na ração, encontrou efeito positivo do uso das farinhas no ganho de peso dos animais (KLASING, 1998).

Em relação à aveia, em trabalhos de HETLAND \& SVIHUS (2001), foram incluídos 0, 40 e $100 \%$ de aveia branca nas dietas, sem e com suplementação de complexo enzimático a base de ßglucanase, protease e xylanase. Estes trabalhos demonstraram aumento significativo no consumo de ração quando a aveia branca foi inserida na alimentação dos frangos. O ganho de peso não apresentou diferença significativa entre os tratamentos, segundo relatam os autores.
Na tabela 3, estão descritos os resultados das análises químicas da carne dos frangos de corte alimentados com as rações testadas. Conforme se observa na tabela 3 , não foram encontrados valores significativamente diferentes $(\mathrm{P}>0,05)$ na carne do peito de frango quando os tratamentos avaliados foram comparados em relação à umidade, às cinzas, à proteína bruta (PB) e ao extrato etéreo (EE), tanto em relação à ração referência quanto às outras rações acrescidas de farinha de peixe e aveia branca. No entanto, houve diferença significativa $(\mathrm{P}<0,05)$ no extrato etéreo da coxa/sobre-coxa dos frangos. As rações com $9 \%$ de farinha de peixe e $10 \%$ de aveia branca aumentaram a quantidade de gordura.

Não são encontrados na literatura nacional e internacional trabalhos referentes à utilização de farinha de peixe e, principalmente, de aveia branca e sua influência na composição química de carcaça de frangos de corte. Porém, a utilização de tabelas de composição química de alimentos para seres humanos necessitam ser constantemente atualizadas.

Em comparação com os valores encontrados na tabela de composição de alimentos da USDA (1999), os teores de lipídios totais desta pesquisa, em relação à carne branca, apresentaram-se inferiores aos

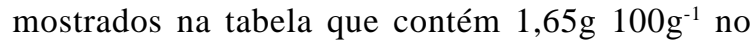
alimento. A quantidade de proteína apresentada pela tabela da USDA (1999) é de 23,2g 100g-1 , encontrandose superior aos achados na atual pesquisa. Na carne da coxa (carne escura) de frango crua, foi relatado na tabela o valor de 4,31g $100 \mathrm{~g}^{-1}$ de lipídios, demonstrando resultados muito próximos aos do presente estudo, e, o valor de $20,08 \mathrm{~g} 100 \mathrm{~g}^{-1}$ de proteínas, valor este considerado superior quando comparado a este trabalho. Em relação à umidade e às cinzas, em ambos os cortes avaliados, os resultados estão em acordo com este estudo. Quando os resultados foram comparados com a Tabela Brasileira de Composição de Alimentos - TACO (2004)-, observou-se que a referida tabela informa valores superiores de lipídios e proteína

Tabela 2 - Valores de desempenho dos frangos de corte no período de 1 a 40 dias de idade

\begin{tabular}{lccc}
\hline Tratamento & Consumo médio total de ração (g) & Peso médio aos 40 dias (g) & Conversão alimentar \\
\hline Ração referência & $3.710 \mathrm{a}$ & $1.970 \mathrm{a}$ & $1,88 \mathrm{a}$ \\
Farinha de peixe 4,5\% & $3.650 \mathrm{a}$ & $2.060 \mathrm{a}$ & $1,77 \mathrm{a}$ \\
Farinha de peixe 9\% & $3.580 \mathrm{a}$ & $2.070 \mathrm{a}$ & $1,73 \mathrm{a}$ \\
Aveia branca 10\% & $3.590 \mathrm{a}$ & $2.180 \mathrm{a}$ & $1,65 \mathrm{a}$ \\
Aveia branca 20\% & $3.720 \mathrm{a}$ & $2.110 \mathrm{a}$ & $1,76 \mathrm{a}$ \\
Erro padrão & 2,70 & 0,09 & 0,03 \\
Coeficiente de variação & 4,89 & 3,21 & 2,94 \\
\hline
\end{tabular}

*Medidas na coluna seguidas de letras diferentes diferem significativamente pelo teste de Tukey $(\mathrm{P}<0,05)$.

Ciência Rural, v.37, n.5, set-out, 2007. 
Tabela 3 - Análise química da carne - peito e coxa/sobrecoxa - dos frangos de corte, alimentados com as rações-teste, em relação à Umidade, às cinzas, à Proteína bruta $(\mathrm{PB})$ e ao Extrato etéreo (EE)

\begin{tabular}{|c|c|c|c|c|c|c|c|c|c|c|c|c|}
\hline & \multicolumn{2}{|c|}{ Umidade (\%) } & \multicolumn{2}{|c|}{ Cinzas (\%) } & \multicolumn{2}{|c|}{$\mathrm{PB}^{*}(\%)$} & \multicolumn{2}{|c|}{$\mathrm{EE}^{*}(\%)$} & \multicolumn{2}{|c|}{$\mathrm{PB} * *(\%)$} & \multicolumn{2}{|c|}{$\mathrm{EE}^{* *}(\%)$} \\
\hline & Peito & $\begin{array}{c}\text { Coxa/ } \\
\text { sobrecoxa }\end{array}$ & Peito & $\begin{array}{c}\text { Coxa/ } \\
\text { sobrecoxa }\end{array}$ & Peito & $\begin{array}{c}\text { Coxa/ } \\
\text { sobrecoxa }\end{array}$ & Peito & $\begin{array}{c}\text { Coxa/ } \\
\text { sobrecoxa }\end{array}$ & Peito & $\begin{array}{c}\text { Coxa/ } \\
\text { sobrecoxa }\end{array}$ & Peito & $\begin{array}{c}\text { Coxa/ } \\
\text { sobrecoxa }\end{array}$ \\
\hline Ração referência & $73,49 a$ & $75,62 \mathrm{a}$ & $1,34 a$ & $1,07 \mathrm{a}$ & $84,96 a$ & $82,93 a$ & $4,64 a$ & $18,45 a$ & $21,48 a$ & $15,99 a$ & $1,23 a$ & $4,51 \mathrm{a}$ \\
\hline $\begin{array}{l}\text { Farinha de peixe } \\
4,5 \%\end{array}$ & $74,78 a$ & $72,88 a$ & $1,16 a$ & $1,04 a$ & $84,79 a$ & $83,17 a$ & $6,32 a$ & $18,83 a b$ & $20,16 a$ & $18,04 a$ & $1,56 a$ & $5,10 \mathrm{ab}$ \\
\hline $\begin{array}{l}\text { Farinha de peixe } \\
9 \%\end{array}$ & 73,68a & $72,21 a$ & $1,15 a$ & $0,82 \mathrm{a}$ & $84,53 a$ & $80,87 a$ & $4,10 \mathrm{a}$ & $22,10 \mathrm{~b}$ & $21,33 a$ & $17,38 a$ & $1,07 \mathrm{a}$ & $6,14 \mathrm{~b}$ \\
\hline $\begin{array}{l}\text { Aveia branca } \\
10 \%\end{array}$ & $74,44 a$ & $73,69 a$ & $1,05 \mathrm{a}$ & $0,97 \mathrm{a}$ & $83,90 a$ & $80,93 a$ & $4,31 \mathrm{a}$ & $22,58 b$ & $20,52 a$ & $16,89 a$ & $1,10 \mathrm{a}$ & $5,93 \mathrm{~b}$ \\
\hline $\begin{array}{l}\text { Aveia branca } \\
20 \%\end{array}$ & $74,46 a$ & $74,69 a$ & $1,34 \mathrm{a}$ & $1,04 \mathrm{a}$ & $84,26 a$ & $80,64 a$ & $4,09 a$ & $18,24 a$ & $20,65 a$ & $16,29 a$ & $1,04 \mathrm{a}$ & $4,61 \mathrm{a}$ \\
\hline Erro padrão & 0,99 & 0,99 & 0,08 & 0,06 & 0,78 & 0,87 & 0,53 & 0,64 & 0,86 & 0,58 & 0,13 & 0,28 \\
\hline $\begin{array}{l}\text { Coeficiente de } \\
\text { variação }\end{array}$ & 2,31 & 2,35 & 11,16 & 10,52 & 1,61 & 1,83 & 19,48 & 5,54 & 7,13 & 5,91 & 19,26 & 9,15 \\
\hline
\end{tabular}

Medidas na coluna seguidas de letras diferentes diferem significativamente pelo teste de Tukey $(\mathrm{P}<0,05)$.

*As análises são expressas em base de matéria seca.

** As análises são expressas em base de matéria natural.

no peito de frango e semelhantes de lipídios e superiores de proteína na coxa/sobrecoxa. Em relação à umidade e às cinzas, a tabela encontra-se com valores semelhantes aos aqui encontrados para a porção do peito e, na coxa, apresenta quantidade superior de umidade, mas próxima à das cinzas.

Alguns autores, porém, mostraram que o nível de gordura dietética poliinsaturada não influencia no conteúdo de lipídio intramuscular do peito (CRESPO \& ESTEVE-GARCIA, 2001), mas KIRCHGESSNER et al. (1993) encontraram conteúdo de gordura mais alta no músculo do peito, com níveis crescentes de ácidos graxos poliinsaturados (PUFA) na dieta. Entretanto, outros autores encontraram conteúdo de lipídio mais baixo no peito de frangos alimentados com dietas enriquecidas com óleos poliinsaturados (SANZ et al., 1999). Tal discrepância no conteúdo de gordura intramuscular no peito pode ser atribuída a vários fatores, como o tipo de procedimento analítico utilizado para extrair gordura das amostras (VILLAVERDE et al., 2003).

Na análise de custo foi verificado que, no tratamento com ração referência, foi gasto $\mathrm{R} \$ 0,72$ por quilo de frango produzido; na ração contento 4,5 e 9\% de farinha de peixe, foram gastos respectivamente $\mathrm{R} \$$ 0,65 e R \$ 0,66; por fim nos tratamentos contendo 10 e $20 \%$ de aveia branca, foram encontrados custos de $\mathrm{R} \$$ 0,64 e R\$ 0,72, respectivamente. Esses resultados demonstram que a farinha de peixe (dois níveis) e $10 \%$ de aveia branca baratearam expressivamente o custo do frango, uma vez que foram em média mais baratas que a ração referência. As rações com 4,5 e 9 \% de farinha de peixe ficaram, respectivamente, com custos 8,9 e $7,89 \%$ menores, enquanto que a ração contendo $10 \%$ de aveia branca mostrou um custo $10,7 \%$ inferior ao da ração controle, indicando a viabilidade econômica da utilização desses alimentos. O tratamento com ração contendo $20 \%$ de aveia branca não teve diferença de custo.

\section{CONCLUSÕES}

A inclusão de farinha de peixe e aveia branca não afetaram negativamente o desempenho zootécnico de frangos de corte. A utilização de $9 \%$ de farinha de peixe e $10 \%$ de aveia branca nas dietas de frangos de corte aumentaram a quantidade de extrato etéreo.

\section{AGRADECIMENTOS E APRESENTAÇÃO}

À Empresa Brasileira de Pesquisa Agropecuária Embrapa Suínos e Aves de Concórdia -SC, pela parceria realizada nas análises químicas; à Indústria Agrária de Entre Rios, pela doação das rações e pintainhos; à Pós-graduação em Ciências Veterinárias da UFPR, que permitiu a realização deste estudo. Parte da dissertação de Mestrado da primeira autora.

\section{REFERÊNCIAS}

ALMEIDA, J.L. Produção e utilização recente de aveia no Brasil. In: REUNIÃO ANUAL DA COMISSÃO BRASILEIRA DE PESQUISA DE AVEIA, 18., 1998, Londrina, PR. Palestras... Londrina: IAPAR, 1998. p.5-15. 
AOAC - ASSOCIATION OF OFFICIAL ANALYTICAL CHEMISTS. Protein (crude) in animal feed. In: Official methods of analysis of AOAC international. 16.ed. Arlington, Virginia: Patricia Cunniff. 1995a. V.1, Cap.4 p.7-9. (method 976.06 G.H.).

AOAC - ASSOCIATION OF OFFICIAL ANALYTICAL CHEMISTS. Fat (crude) or ether extract in animal feed. In: . Official methods of analysis of AOAC international. 16.ed. Arlington, Virginia: Patricia Cunniff. 1995b. V.1, Cap.4, 17p.

BUTOLO, J.E. Qualidade de ingredientes na alimentação animal. Campinas: Colégio Brasileiro de Nutrição Animal, 2002. 430p.

CRESPO, N.; ESTEVE-GARCIA, E. Dietary fatty acid profile modifies abdominal fat deposition in broiler chickens. Poultry Science, v.80, p.71-78, 2001

FAO - Organización de las Naciones Unidas para la Agricultura y la Alimentación. Tabla de composición de alimentos de américa latina. Roma: Oficina Regional para América Latina y el Caribe/ LATINFOODS, 2002. p.1-24.

FERREIRA, D.F. SISVAR - Sistema de análise de variância - Versão 4.6. Lavras: UFLA, 1999.

FIALHO, E.T. Alimentos alternativos para suínos. Lavras: UFLA/FAEPE, 2004. 228p.

HETLAND, H.; SVIHUS, B. Effect of oat hulls on performance, gut capacity and feed passage time in broiler chickens source. British Poultry Science, v.42, n.3, p.354-361, 2001

INSTITUTO ADOLFO LUTZ. Normas analíticas - Métodos químicos e físicos para análise de alimentos. São Paulo: Instituto Adolfo Lutz, 1985. 1v.

KIRCHGESSNER, M. et al. Einsatz von fetten mit hohen anteilen an freien fettsaren in der broilermast. 2. Wachstum sowie qualitat von schlachtkorper, fleisch und fett bei stufenweisem austausch von gesattigten durch ungesattigte fettsauren. Archives Geflugelk, v.57, p.265-274, 1993.

KLASING, K.C. Nutritional modulation of resistance to infectious diseases. Poultry Science, v.77, n.8, p.1119-1125, 1998.

LÀSZTITY, R. Oat grain - A wonderful reservoir of natural nutrients and biologically active substances. Food Review International, v.14, n.1, p.99-119, 1998.

MAIGUALEMA, M.A.; GERNAT, A.G. The effect of feeding elevated levels of tilapia (Oreochromus niloticus) by-product meal on broiler performance and carcass characteristics.
International Journal of Poultry Science, v.2, n.3, p.195199, 2003.

MORALLES-ULLOA, D.F.; OETTERER, M. Bioconservação de resíduos da indústria pesqueira. Ciência e Tecnologia de Alimentos, Campinas, v.15, n.3, p.206-214, 1995.

NASCIMENTO, W.G. et al. Efeito da substituição do milho pelo triticale sobre o desempenho de novilhas nelore confinadas. Capturado em: 08 de mar. de 2005. On line. Disponível na Internet: http://www.cca.uem.br/anu0600.htm.

PONCE, L.E.; GERNAT, A.G. The effect of using different levels of tilapia by-product meal in broiler diets. Poultry Science, v.81, p.1045-1049, 2002.

RIBEIRO, P.A.P. et al. Manejo alimentar de peixes. Minas Gerais: NAQUA - Núcleo de Estudos em Aquacultura, UFLA, 2005. V.1, p.1-13. (Boletins Técnicos).

RICHETTI, A.; SANTOS, A.C. O sistema integrado de produção de frango de corte em minas gerais: uma análise sob a ótica da ECT. Organizaç̃̃es Rurais e Agroindustriais - Revista Eletrônica de Administração, v.2, n.2, 2000. Capturado em: 06 de mar. de 2004. On line. Disponível na Internet: http://www.dae.ufla.br/cedoc/artigo03200.doc.

ROSTAGNO, H.S. et al. Tabelas brasileiras para aves e suínos. Composição de alimentos e exigências nutricionais. Viçosa: Universidade Federal de Viçosa, 2000. 141p.

SANZ, M. et al. Higher lipid accumulation in broilers fed on saturated fats than in those fed on unsaturated fats. British Poultry Science, v.40, n.1, p.95-101, 1999.

SILVA, J.C.T. Desempenho do setor avícola. São Paulo-SP. Capturado em: 06 de jan. de 2005. On line. Disponível na Internet: http://www.aveseovos.com.br/avicult.html.

TACO - TABELA BRASILEIRA DE COMPOSIÇÃO DE ALIMENTOS. Núcleo de estudos e pesquisas em alimentação. Campinas: UNICAMP - NEPA, 2004. 44p.

USDA. Nutrient database for standard reference. Release 13, NDB n.10199, 1999. Capturado em: 06 de jan. de 2005. On line. Disponível na Internet: http://www.ars.usda.gov/main/ site_main.htm?Modecode $=12354500$.

VILLAVERDE, C. et al. Total fatty acid quantification as an estimator of total body fat content in broilers fed unsaturated diets. In: EUROPEAN SYMPOSIUM ON THE QUALITY OF POULTRY MEAT, 16., 2003, SaintBrieuc, France. Proceedings... SaintBrieuc: Geneviève Clement, 2003. V.1. p.265-271. 